\title{
Wireless sensor network to identify the reduction of meteorological gradients in greenhouse in subtropical conditions
}

\author{
Thais Queiroz Zorzeto Cesar, Paulo Ademar Martins Leal, Omar Carvalho Branquinho, Felipe Antonio \\ Moura Miranda
}

School of Agricultural Engineering (FEAGRI), University of Campinas (UNICAMP), Brazil

\begin{abstract}
Spatial and temporal monitoring of temperature and relative humidity is essential for greenhouse management, therefore, wireless sensor networks (WSN) can offer crucial advantages. The objective of this work was to use a WSN to characterize and map the horizontal and vertical variability of air temperature and relative humidity inside a greenhouse using five different configurations. The configurations were based on combinations between the following actuating mechanisms: i) mechanical ventilation (by two exhaust fans); ii) natural ventilation (through the roof vent openings); iii) shading through the use of thermo-reflective screen. The WSN was designed with 45 spatially distributed measuring points, and the air temperature and relative humidity were recorded automatically every 30 seconds, for ten consecutive days, for each configuration. Our results show that the horizontal and vertical homogeneity of the meteorological elements depends on the actuating mechanism used in the greenhouse. Mechanical ventilation approximated the temperature and relative humidity of the indoor and outdoor air, with a homogeneous horizontal distribution throughout the environment. Opening the roof vent reduced vertical gradients of temperature and relative humidity. Our observations also showed that the combination of the use of roof vent openings with mechanical ventilation is an effective way to achieve horizontal homogeneity of meteorological elements.
\end{abstract} Correspondence: Thais Queiroz Zorzeto Cesar, School of Agricultural
Engineering (FEAGRI), University of Campinas (UNICAMP), Brazil.
E-mail: thaisqzc@unicamp.br

Key words: Exhaust fan; protected cultivation; SHT75; wireless sensor network; roof vent openings; windows.

Funding: this work was supported by the São Paulo Research Foundation [grant numbers 2013/11953-9] and the Coordination of Superior Level Staff Improvement.

Received for publication: 9 July 2020.

Accepted for publication: 28 August 2020.

(C) Copyright: the Author(s), 2021

Licensee PAGEPress, Italy

Journal of Agricultural Engineering 2021; LII:1105

doi:10.4081/jae.2020.1105

This article is distributed under the terms of the Creative Commons Attribution Noncommercial License (by-nc 4.0) which permits any noncommercial use, distribution, and reproduction in any medium, provided the original author(s) and source are credited.

\section{Introduction}

Knowing the behaviour of meteorological elements, such as temperature and relative humidity in a greenhouse, is essential to exploit the benefits of protected cultivation. As the air moves inside the greenhouse, gradients of temperature and relative humidity are formed throughout the structure (Chen, 2003). These gradients can result in a heterogeneous microclimate, which may be undesirable for crops (Teitel et al., 2010) and for workers (García-Ruiz et al., 2018; López -Martínez et al., 2018).

The wireless sensor networks (WSN) offer several advantages, both for monitoring the greenhouse microclimate, mapping the heterogeneity of meteorological elements, or controlling the actuation mechanisms. However, the location of sensors inside the greenhouse is essential, as their measurements can be used to control all actuation mechanisms. Also, it is possible to obtain different values at different points in the internal microclimate over time (Narasimhan et al., 2007).

The gradients of meteorological elements are related to several factors such as solar radiation, mass transfer by convection, and dynamics of air movement due to differences in internal and external temperature. The internal conditions of the greenhouse microclimate can affect crops, with an unequal growth of plants (Teitel et al., 2010), and the safety and productivity of workers. Therefore, measurements of thermal heterogeneity along the vertical and horizontal axes are taken to assess working conditions (García-Ruiz et al., 2018; López -Martínez et al., 2018).

In literature, several studies reported different results regarding the distribution of temperature and relative humidity, which may be ascribed, among other reasons, to discrepancies between crops and greenhouse configurations, with different microclimate conditions and technological mechanisms, such as ventilation and cooling systems.

Several studies evaluated the horizontal distribution in environments with mechanical ventilation systems (Balendonck et al., 2014), natural ventilation (Ferentinos et al., 2017; García-Ruiz et $a l ., 2018$ ) and natural ventilation associated with mechanical ventilation (Kittas et al., 2012; López et al., 2013). As to the vertical distribution, other studies also evaluated greenhouse microclimates with different systems, such as natural ventilation (Suay et al., 2008), or mechanical ventilation and evaporative cooling (Kutta and Hubbart, 2014; Zorzeto and Leal, 2017).

The position of the greenhouse sensors can reflect different values at different points in the internal microclimate over time (Narasimhan et al., 2007). Patterns of heterogeneity were found as a function of the incidence of sunlight and time of day, while the majority of homogeneous days was correlated with cloudy days (García-Ruiz et al., 2018). In a natural ventilated greenhouse, in Almería, the authors found air temperature heterogeneity mainly in the central hours of the day and in the horizontal dimension rather than vertically (measured from $0.23 \mathrm{~m}$ to $1.56 \mathrm{~m}$ from the floor). 
Despite the potential for uneven distribution of temperature and relative humidity of the air throughout a greenhouse, the common practice is to install a single sensor for measuring both elements at a fixed point assumed to be representative of the entire microclimate (Pawlowski et al., 2009), regardless of the operating system used. This approach is motivated by the consideration that additional sensors require additional infrastructure, increasing the complexity and costs associated with controlling the microclimate, such as equipment and maintenance (Pawlowski et al., 2009).

The WSNs are now being used advantageously to monitor and map the distribution of meteorological elements in the greenhouse microclimate (Bojacá et al., 2009; Park and Park, 2011; Kutta and Hubbart, 2014; Balendonck et al., 2014; Vox et al., 2014; Zorzeto and Leal, 2017; López-Martínez et al., 2018; García-Ruiz et al., 2018). However, the number of sensors necessary for proper monitoring is a subject that still needs to be studied, in different configurations of the available mechanisms. It is relevant because an adequate control of the actuation mechanisms, especially concerning temperature and relative humidity, is one of the main tools for managing operations in a greenhouse (Bojacá et al., 2009).

In a WSN, the system collects information from the internal microclimate, stores it in a database, checks it, and can automatically and remotely manage the retrieved data. WSNs provide many advantages. For instance, they make it possible to customize projects based on specific needs in terms of monitoring and controlling the systems in the microclimate, without being invasive or requiring cabling infrastructure and layout changes (Vox et al., 2014). Therefore, this also implies cost and time savings.

The spatial homogeneity of some elements is key to achieve one of the main objectives of farming in protected environments: the uniform growth of plants with good production quality (Balendonck et al., 2010). Therefore, it is necessary to know the microclimate and understand this complex system. Hence, field measurements are essential to achieve any improvement in this regard. Focusing on quantity and quality of data collected in the area, especially exploring spatial variations, is necessary to monitor and control accurately the performance of the systems and to develop and validate models in protected microclimates based on real conditions (Tanny, 2013).

In order to better evaluate the homogeneity of climatic variables in a greenhouse, our research work was aimed to characterize both the horizontal and vertical gradients of air temperature and relative air humidity inside a greenhouse with a WSN. To better cover all scenarios, five different combinations of shading, mechanical and natural ventilation mechanisms were used.

In relation to these objectives, the innovative elements of this work were that we designed a wireless sensor network with a high density of physical points and frequency of data collection in a greenhouse, and mapped the meteorological elements in the environment according to the availability of the actuating mechanisms. The areas with natural, mechanical, and shading ventilation presented a homogeneous distribution of temperature and relative humidity at $1.2 \mathrm{~m}$ and $2.4 \mathrm{~m}$ from the floor level. Furthermore, the association of roof vent openings with mechanical ventilation reduced the vertical heterogeneity of the meteorological elements.

\section{Materials and methods}

The experiment was carried out in a greenhouse, located in the experimental field of the Faculty of Agricultural Engineering (FEAGRI), of the State University of Campinas (UNICAMP), in Campinas-Brazil (22 $2^{\circ} 49^{\prime} 06^{\prime \prime} \mathrm{S}, 47^{\circ} 03^{\prime} 40^{\prime}$ ' W, $635 \mathrm{~m}$ above sea level). The greenhouse had a floor area of $117 \mathrm{~m}^{2}(6.4 \mathrm{~m}$ wide, 18.3 $\mathrm{m}$ long, $4.0 \mathrm{~m}$ high, $5.5 \mathrm{~m}$ total height). The greenhouse had arched roof and roof vent openings to the windward and leeward sides, both free of obstacles. The openings were coated with the screen with anti-aphid screen. The entire greenhouse (roof and sides) was covered with a low-density polyethylene film, with the characteristics of $150 \mu \mathrm{m}$ thick light diffuser and an anti-ultraviolet treatment.

The greenhouse was equipped with mechanisms of natural and mechanical ventilation and shading. The natural ventilation occurred only by the roof vent openings. The mechanical ventilation system included two exhausters on the northern side of the greenhouse (models EM36, below the gutter, and ED24, above the gutter). The shading had a thermo-reflective screen with $50 \%$ wave transmissivity, installed horizontally at the height of the gutter, movable, pulled by a reducing motor with double limit switch.

To evaluate the meteorological gradients, we designed the configurations corresponding to the combinations between the operating systems of the greenhouse: i) fully closed; ii) mechanical ventilation, with both connected exhaust fans (referred to as MV); iii) mechanical ventilation with both exhausters and shading (referred to as MV-S); iv) mechanical ventilation with the lower exhaust fan on, and natural ventilation through the roof vent openings (referred to as MV1-NV); v) mechanical ventilation, with both exhaust fans turned on, and natural ventilation through the roof vent openings (referred to as MV2-NV).

In several studies on the monitoring or simulation of internal weather conditions, the authors did not consider the effects due to the presence of plants (Sapounas et al., 2008; Bojacá et al., 2009; Ferentinos et al., 2017), or the concrete floor inside greenhouses (Suay et al., 2008). Due to the difficulties of maintaining plants with the same development characteristics inside the greenhouse, in each of the proposed configurations, we decided to plant grass (São Carlos species). The plants were pruned, maintaining a height of $5 \mathrm{~cm}$, in each configuration. An irrigation system was installed with 12 hoses along the longitudinal axis of the greenhouse, 500 $\mathrm{mm}$ apart, with internal self-compensating drippers $\left(1.6 \mathrm{~L} \mathrm{~h}^{-1}\right)$ every $500 \mathrm{~mm}$, and a control unit programmed to switch on at 9 a.m., 12 a.m. and 4 p.m., for 5 minutes, every day.

The WSN and its infrastructure installed in the greenhouse had the role of reading and storing the microclimate data, according to each specific configuration. The WSN motes, Radiuino BE900 modules, were responsible for reading the sensors and send their data to a central PC. The central PC was responsible for storing the received data, according to each scenario analysed.

The WSN had 45 sensors arranged in three layers, as shown in Figure 1, being: 21 of them with two SHT75 transducers each, positioned at $1.2 \mathrm{~m}$ and $2.4 \mathrm{~m}$ above the floor (providing 42 points below the right foot), and three equipped with one SHT75 transducer each, $4.5 \mathrm{~m}$ from the floor level. In the geometric centre of the greenhouse, a wind speed sensor (Argent Data Systems, Weather Sensor Assembly, part number 80422) and a photosynthetically active radiation sensor (RFA, Quantum, Licor) were also installed.

Porous capsules protected the SHT75 sensors (accuracy of $\pm 0.3^{\circ} \mathrm{C}$ for temperature and $\pm 1.8 \%$ for relative air humidity) and the porous capsules were housed in PVC (polyvinyl chloride) tubes (400 $\mathrm{mm}$ in length and $100 \mathrm{~mm}$ in diameter), coated with an aluminium foil for protection against the effects of undesired radiation, and with fans (Akasa, $12 \mathrm{~V}, 0.25 \mathrm{~A}$ ) at its upper end at all measurement points.

The horizontal gradient was evaluated at a height of $1.2 \mathrm{~m}, 2.4$ $\mathrm{m}$ and $4.5 \mathrm{~m}$ (Figure 1B) and in the positions (width, length, height): the horizontal profile at a height of $1.2 \mathrm{~m}$ with 21 points from $(1,1,1)$ to $(3,7,1)$ (Figure $1 \mathrm{~A})$; the horizontal profile at a 
height of $2.4 \mathrm{~m}$ also with 21 points from $(1,1,2)$ to $(3,7,2)$ (Figure 1A); and the horizontal line at a height of $4.5 \mathrm{~m}$ with three points, in positions $(2,2,3),(2,4,3)$ and $(2,6,3)$ (Figure 1A). The vertical gradient, in turn, was evaluated in the central profile, characterized by nine points, located at $(2,2),(2,4),(2,6)$ at a height of $1.2 \mathrm{~m}, 2.4$ $\mathrm{m}$, and $4.5 \mathrm{~m}$ (Figure $1 \mathrm{~A})$.

A meteorological station was installed $2.0 \mathrm{~m}$ from the apex of the greenhouse and a height of $7.0 \mathrm{~m}$ to collect external data on temperature, relative humidity, speed, and wind direction, as shown in Figure 1A.

The sensors read the air temperature and relative humidity every 30 seconds for each configuration for ten consecutive days. The experiment occurred from June to August 2014.

Hourly averages were calculated from these retrieved data. Statistically, they were analysed at critical times (WMO - World Meteorological Organization, 1953): 3 a.m., 9 a.m., 3 p.m. and 9 p.m., for 45 measuring points during ten days of testing, in a completely randomized design for each greenhouse configuration. These data were tested with averages test and compared to the Tukey test with 5\% probability, using the software Assistat.

For comparison between the internal and external microclimates, from the calculated hourly averages, the daytime results included the period from 7 a.m. to 6 p.m. and the difference between the ambient air temperatures and relative humidity.

For the evaluation of horizontal gradients, the standard deviation was used as an indicator of the distribution homogeneity (Balendonck et al., 2010, 2014; Kittas et al., 2012; Kutta and Hubbart, 2014), for each of the heights (1.2 m, $2.4 \mathrm{~m}$ and $4.5 \mathrm{~m}$ ) and for each daytime ( 7 a.m. to 6 p.m.). In order to consider a microclimate as horizontally homogeneous, the Dutch
Environmental Certification Organization (Stichting Milieukeur, 2010, cited by Balendonck et al., 2010) establish that this must remain in the range of $\pm 0.75^{\circ} \mathrm{C}$ for temperature and $\pm 3 \%$ for relative humidity. The weather maps were generated using the software Surfer.

For the vertical gradient, from the values obtained every 30 seconds, the hourly averages of temperature and relative air humidity were calculated, with a repetition of ten days of testing, for each height. The results were divided into periods: day (7 a.m. to 6 p.m.) and night ( 7 p.m. to 6 a.m.). The weather maps were generated using the software Surfer.

\section{Results and discussion}

\section{Photosynthetically active radiation analysis}

Photosynthetically active radiation was similar between the configurations, except for the configuration with mechanical ventilation and shading (MV-S) and with mechanical ventilation with both exhausters and natural ventilation (MV2-NV), as shown in Table 1 . The screen, installed horizontally at the height of the gutter, had a $50 \%$ wave transmissivity, therefore, it allowed the passage of only $50 \%$ of the radiation incident on the screen in the greenhouse, reflecting the lowest values measured internally. The configuration with roof vent openings, and both exhausters received more radiation than in other microclimates, influencing the internal conditions, as shown in Table 1.

$\mathbf{A}$

B

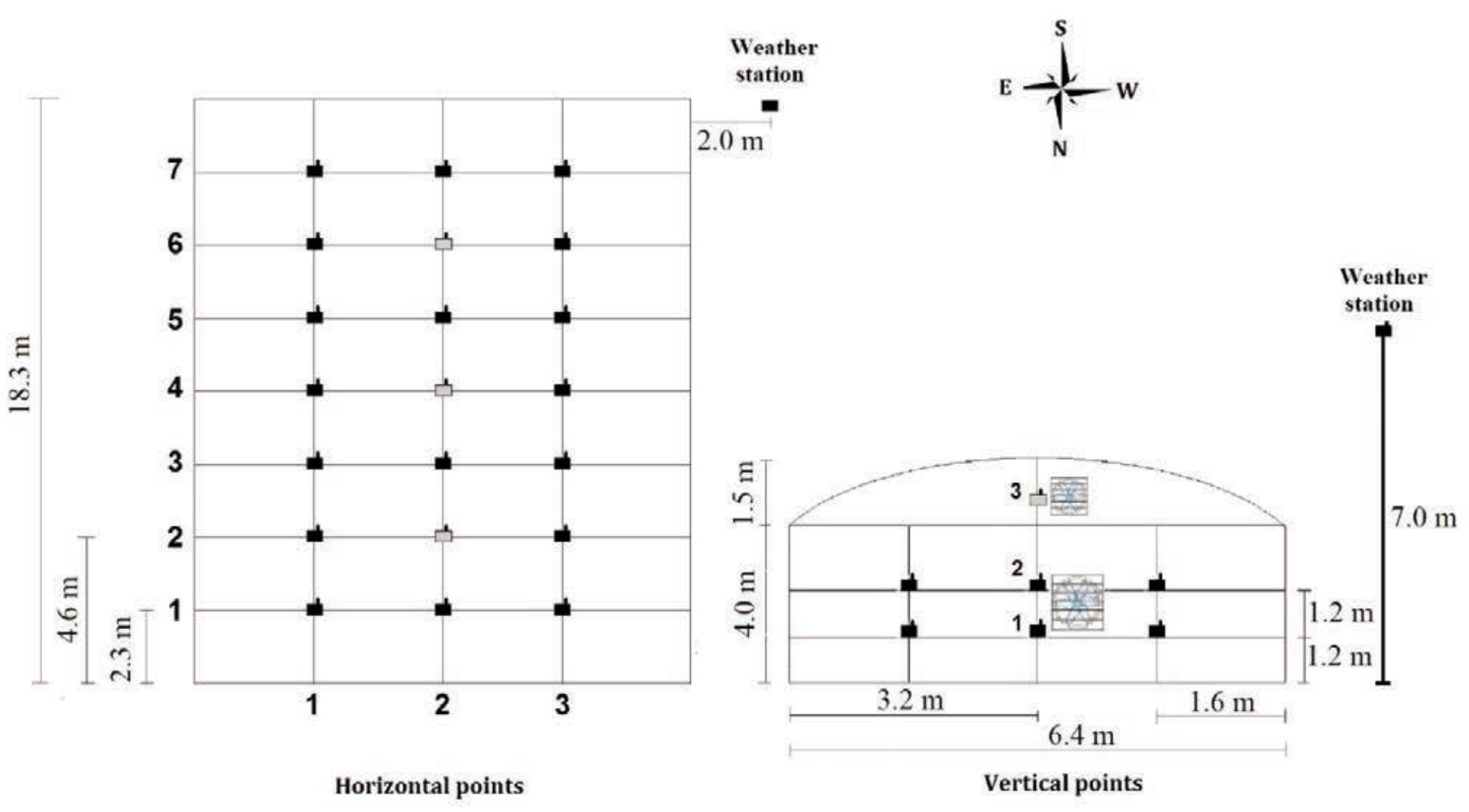

Figure 1. Wireless sensor network with (A) horizontal and (B) vertical measurement points. 


\section{Differences between indoor and outdoor environments}

In general, the differences between indoor and outdoor environments remained below $1{ }^{\circ} \mathrm{C}$ for air temperature and between $\pm 1 \%$ for relative air humidity, that is, below the accuracy range of the sensors, except for the configuration with the fully enclosed greenhouse (control), whose differences were $3.11^{\circ} \mathrm{C}$ for temperature and $11 \%$ for relative humidity above the external conditions (Table 1). When the greenhouse was completely closed, there was no renewal of the indoor air, the transfer of heat energy between the microclimates was limited to conduction and convection through the area covered with plastic, the accumulation of heat and water vapor, due to the evapotranspiration of the plants and evap- oration of irrigation water, became evident. With mechanical ventilation, either with both exhaust fans turned on (MV), or associated with shading with the stretched thermo-reflective screen (MV-S), there was a renewal of internal air, which tended to become similar to external, thus reducing the differences between the two microclimates. By adding the roof vent openings to the exhaust fans (MV2-NV), there was an increase in the difference in air temperature. The associated use of mechanical ventilation would not always imply less variation between the indoor and outdoor environments (López et al., 2013). The authors showed in a Mediterranean greenhouse that with fans placed at $4 \mathrm{~m}$ from the side vents, the entrance of outside air was insufficient to reduce the inside temperature on hot days with little wind. They recommend-

Table 1. Average daytime values (7 a.m. to 6 p.m.) for external and internal air temperature (Te and Ti), external and internal relative humidity (RHe and RHi), external and internal wind speed (Ve and Vi), internal photosynthetically active radiation (PARi). The difference between Te and $\mathrm{Ti}$, and for RHe and RHi are present respectively in columns $\mathrm{T}$ and $\mathrm{RH}$.

\begin{tabular}{|c|c|c|c|c|c|c|c|c|c|}
\hline Configuration & $\begin{array}{l}\mathrm{Te} \\
\left({ }^{\circ} \mathrm{C}\right)\end{array}$ & $\begin{array}{c}\mathrm{Ti} \\
\left({ }^{\circ} \mathrm{C}\right)\end{array}$ & $\begin{array}{c}\Delta \mathrm{T} \\
\left({ }^{\circ} \mathrm{C}\right)\end{array}$ & $\begin{array}{l}\text { RHe } \\
(\%)\end{array}$ & $\begin{array}{l}\text { RHi } \\
(\%)\end{array}$ & $\begin{array}{l}\Delta \mathrm{RH} \\
(\%)\end{array}$ & $\begin{array}{c}\text { PARi } \\
\left(\mu \mathrm{mol} . \mathrm{s}^{-1} \mathrm{~m}^{-2}\right)\end{array}$ & $\begin{array}{c}\mathrm{Ve} \\
\left(\mathrm{ms}^{-1}\right)\end{array}$ & $\begin{array}{c}\mathrm{Vi} \\
\left(\mathrm{ms}^{-1}\right)\end{array}$ \\
\hline $\mathrm{FC}$ & 21.25 & 24.36 & 3.11 & 64 & 75 & 11 & 246.31 & 7.7 & 0.0 \\
\hline MV & 22.73 & 22.88 & 0.15 & 52 & 53 & 1 & 231.16 & 5.4 & 0.0 \\
\hline MV-S & 19.81 & 20.19 & 0.38 & 66 & 66 & 0 & 117.22 & 9.2 & 0.2 \\
\hline MV1-NV & 19.09 & 19.88 & 0.79 & 65 & 64 & -1 & 204.21 & 6.6 & 0.0 \\
\hline MV2-NV & 22.33 & 23.27 & 0.94 & 48 & 47 & -1 & 325.74 & 8.3 & 0.1 \\
\hline
\end{tabular}

FC, fully closed greenhouse; MV, mechanical ventilation, with both exhaust fans connected; MV-S, mechanical ventilation with both exhausters and shading; MV1-NV, mechanical ventilation, with the lower exhaust fan on, and natural ventilation through the roof vent openings; MV2-NV, mechanical ventilation, with both exhaust fans turned on, and natural ventilation, through the roof vent openings.

Table 2. Air temperature (T) and relative humidity $(\mathrm{RH})$ at a hight of $1.2 \mathrm{~m}, 2.4 \mathrm{~m}$ and $4.5 \mathrm{~m}$, for critical times $(3$ a.m., 9 a.m., 3 p.m. and 9 p.m.) and configurations.

\begin{tabular}{|c|c|c|c|c|c|c|c|c|c|c|}
\hline \multirow{2}{*}{$\begin{array}{l}\text { Variable } \\
\mathrm{T}\left({ }^{\circ} \mathrm{C}\right)\end{array}$} & \multirow[t]{2}{*}{ Configuration } & \multirow{2}{*}{$\begin{array}{l}\text { Height } \\
1.2 \mathrm{~m}\end{array}$} & \multicolumn{2}{|l|}{3 a.m. } & \multicolumn{2}{|c|}{9 a.m. } & \multicolumn{2}{|l|}{3 p.m. } & \multicolumn{2}{|l|}{9 p.m. } \\
\hline & & & 13.44 & $* *$ & 21.87 & $* *$ & 28.95 & $* *$ & 15.40 & ** \\
\hline & $\mathrm{FC}$ & $2.4 \mathrm{~m}$ & 13.46 & $* *$ & 22.51 & $*$ & 29.90 & $* *$ & 15.51 & ** \\
\hline & & $4.5 \mathrm{~m}$ & 13.66 & ns & 25.09 & $*$ & 35.04 & $\mathrm{~ns}$ & 15.91 & ns \\
\hline & & $1.2 \mathrm{~m}$ & 14.36 & $* *$ & 18.34 & $* *$ & 27.06 & $* *$ & 18.40 & ** \\
\hline & MV & $2.4 \mathrm{~m}$ & 14.58 & $* *$ & 18.75 & $* *$ & 27.59 & $* *$ & 18.75 & ** \\
\hline & & $4.5 \mathrm{~m}$ & 14.67 & ns & 22.72 & ns & 31.55 & ns & 18.90 & ns \\
\hline & & $1.2 \mathrm{~m}$ & 14.29 & $* *$ & 17.41 & ns & 22.76 & $* *$ & 16.82 & ** \\
\hline & MV-S & $2.4 \mathrm{~m}$ & 14.30 & $* *$ & 17.65 & $* *$ & 22.99 & $* *$ & 16.80 & ** \\
\hline & & $4.5 \mathrm{~m}$ & 14.10 & ns & 21.48 & ns & 27.95 & $*$ & 16.62 & ns \\
\hline & & $1.2 \mathrm{~m}$ & 13.66 & $* *$ & 17.26 & $* *$ & 23.01 & $* *$ & 15.84 & ** \\
\hline & MV1-VN & $2.4 \mathrm{~m}$ & 13.85 & $* *$ & 17.34 & $* *$ & 23.11 & $* *$ & 16.06 & ** \\
\hline & & $4.5 \mathrm{~m}$ & 14.13 & ns & 17.73 & ns & 23.46 & ns & 16.37 & ns \\
\hline & & $1.2 \mathrm{~m}$ & 13.51 & $* *$ & 19.24 & $* *$ & 28.02 & $* *$ & 18.13 & ** \\
\hline & MV2-VN & $2.4 \mathrm{~m}$ & 13.70 & $* *$ & 19.35 & $* *$ & 28.10 & $* *$ & 18.62 & ** \\
\hline & & $4.5 \mathrm{~m}$ & 14.01 & ns & 20.35 & $*$ & 28.35 & ns & 18.98 & $*$ \\
\hline RH (\%) & & $1.2 \mathrm{~m}$ & 99 & ns & 84 & $*$ & 62 & $* *$ & 92 & ns \\
\hline & FC & $2.4 \mathrm{~m}$ & 98 & ns & 82 & $*$ & 63 & $* *$ & 90 & ns \\
\hline & & $4.5 \mathrm{~m}$ & 97 & ns & 69 & ns & 46 & ns & 86 & ns \\
\hline & & $1.2 \mathrm{~m}$ & 80 & ns & 70 & $* *$ & 40 & $* *$ & 63 & ns \\
\hline & MV & $2.4 \mathrm{~m}$ & 78 & $* *$ & 67 & ns & 38 & $* *$ & 60 & ** \\
\hline & & $4.5 \mathrm{~m}$ & 77 & ns & 53 & ns & 30 & ns & 59 & ns \\
\hline & & $1.2 \mathrm{~m}$ & 89 & $*$ & 77 & $* *$ & 56 & $* *$ & 77 & ** \\
\hline & MV-S & $2.4 \mathrm{~m}$ & 88 & $* *$ & 76 & $* *$ & 54 & $* *$ & 76 & $* *$ \\
\hline & & $4.5 \mathrm{~m}$ & 89 & ns & 62 & $*$ & 42 & $*$ & 77 & ns \\
\hline & & $1.2 \mathrm{~m}$ & 86 & $* *$ & 74 & $* *$ & 54 & $* *$ & 78 & $* *$ \\
\hline & MV1-VN & $2.4 \mathrm{~m}$ & 84 & $* *$ & 73 & $* *$ & 53 & $* *$ & 76 & $* *$ \\
\hline & & $4.5 \mathrm{~m}$ & 83 & $*$ & 71 & ns & 51 & ns & 75 & $* *$ \\
\hline & & $1.2 \mathrm{~m}$ & 80 & $* *$ & 61 & $* *$ & 32 & $* *$ & 57 & $* *$ \\
\hline & MV2-VN & $2.4 \mathrm{~m}$ & 78 & $* *$ & 60 & $* *$ & 32 & $* *$ & 55 & $* *$ \\
\hline & & $4.5 \mathrm{~m}$ & 77 & $*$ & 57 & ns & 30 & ns & 53 & $*$ \\
\hline
\end{tabular}

FC, fully closed greenhouse; MV, mechanical ventilation, with both exhaust fans connected; MV-S, mechanical ventilation with both exhausters and shading; MV1-NV, mechanical ventilation, with the lower exhaust fan on, and natural ventilation through the roof vent openings; MV2-NV, mechanical ventilation, with both exhaust fans turned on, and natural ventilation, through roof vent openings. ns, non-significant; *significant $(0.01 \leq \mathrm{P}<0,05)$; ** significant $(\mathrm{P}<0.01)$. Using Tukey's test at $5 \%$ probability. 
ed to place the fans closer to the side vents to allow an additional increase of the air exchange rate of greenhouses. In their study, the greenhouse was equipped with a single roof vent opening to the windward side and two side vents. Therefore, when no fans were used, air entered through the roof vent and go out through both side vents, thus affecting the natural ventilation. In our study, with the exhaust fan on the northern side placed closer to the roof vent openings, air entered through the roof vent next to this exhauster, flowing contrary to the thermal effect and to the natural exhaustion through the roof vent openings, therefore, affecting the ventilation of the greenhouse.

\section{Horizontal profiles analysis}

The statistical analysis is shown in Table 2. Data for relative humidity were not significant. For air temperature measured at 45 points, no significant differences were found between the temperature values for each configuration at $1 \%$ or $5 \%$ of significance for heights at $1.2 \mathrm{~m}$ and $2.4 \mathrm{~m}$. This shows that the data, measured at each horizontal plane and for each configuration, tended to be homogeneous. Thereby, the criteria for considering the microclimate horizontally homogeneous was determined by the Dutch Environmental Certification Organization (Stichting Milieukeur, 2010, cited by Balendonck et al., 2010): standard deviation should remain in the range of $\pm 0.75^{\circ} \mathrm{C}$ for temperature and $\pm 3 \%$ for relative humidity. Table 3
Table 3. Standard deviation for air temperature (sT) and relative humidity (sRH) for daytime readings (7 a.m. to 6 p.m.), at a height of $1.2 \mathrm{~m}, 2.4 \mathrm{~m}$ and $4.5 \mathrm{~m}$ and the configurations.

\begin{tabular}{lccc} 
Configuration & Height & sT $\left({ }^{\circ} \mathrm{C}\right)$ & sRH (\%) \\
\multirow{3}{*}{ FC } & $1.2 \mathrm{~m}$ & 0.27 & 3 \\
& $2.4 \mathrm{~m}$ & 0.30 & 2 \\
\multirow{3}{*}{ MV } & $4.5 \mathrm{~m}$ & 1.00 & 3 \\
& $1.2 \mathrm{~m}$ & 0.25 & 2 \\
& $2.4 \mathrm{~m}$ & 0.31 & 1 \\
MV-S & $4.5 \mathrm{~m}$ & 0.24 & 1 \\
& $1.2 \mathrm{~m}$ & 0.28 & 1 \\
& $2.4 \mathrm{~m}$ & 0.23 & 1 \\
MV1-VN & $4.5 \mathrm{~m}$ & 0.15 & 0 \\
& $1.2 \mathrm{~m}$ & 0.16 & 0 \\
& $2.4 \mathrm{~m}$ & 0.21 & 0 \\
MV2-VN & $4.5 \mathrm{~m}$ & 0.98 & 2 \\
& $1.2 \mathrm{~m}$ & 0.18 & 0 \\
\hline
\end{tabular}

FC, fully closed greenhouse; MV, mechanical ventilation, with both exhaust fans connected; MV-S mechanical ventilation with both exhausters and shading; MV1-NV, mechanical ventilation, with the lower exhaust fan on, and natural ventilation through the roof vent openings; MV2-NV, mechanical ventilation, with both exhaust fans turned on, and natural ventilation, through roof vent openings.

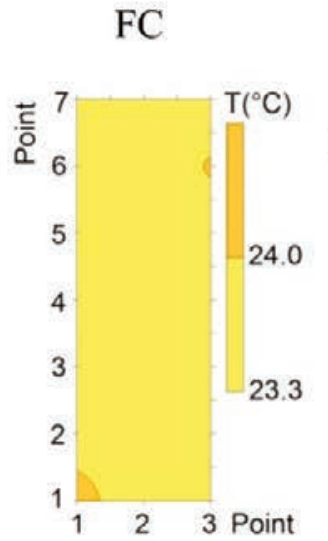

(A)

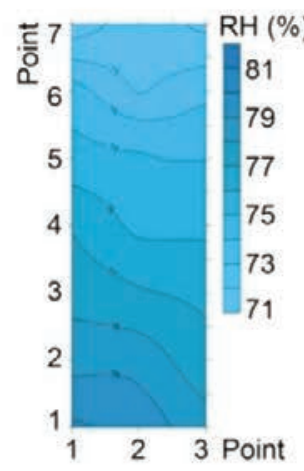

(F)

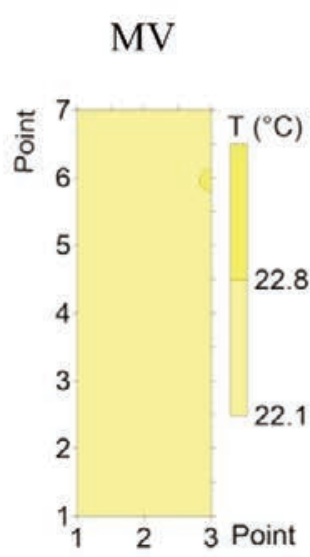

(B)

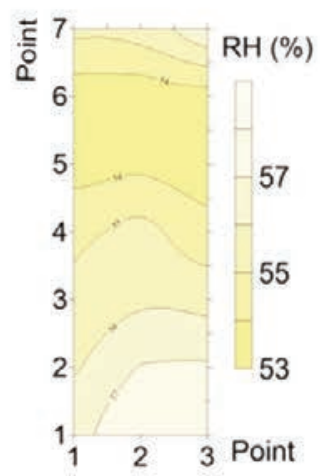

(G)

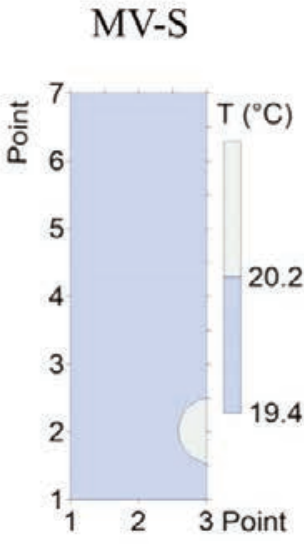

(C)

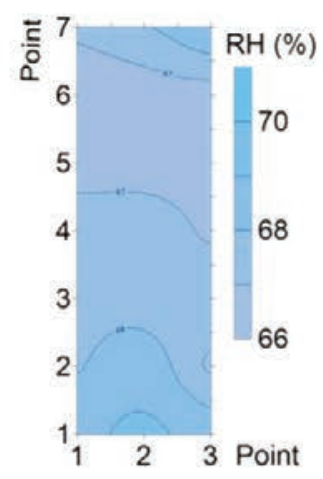

(H)

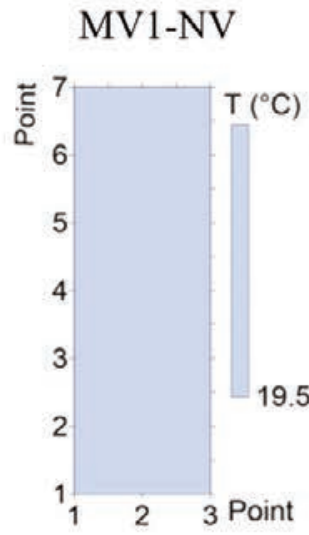

(D)

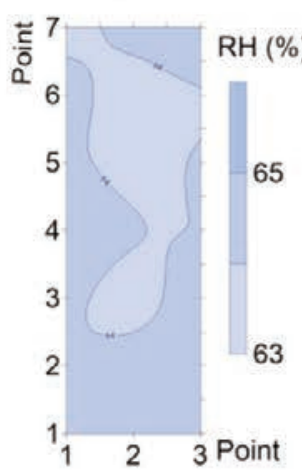

(I)
MV2-NV

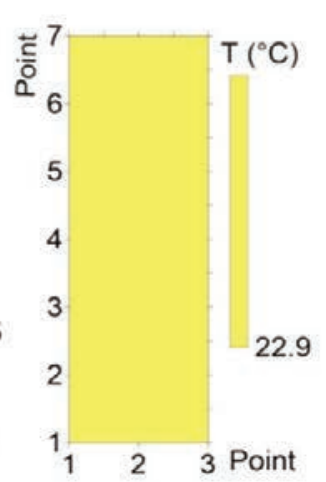

(E)

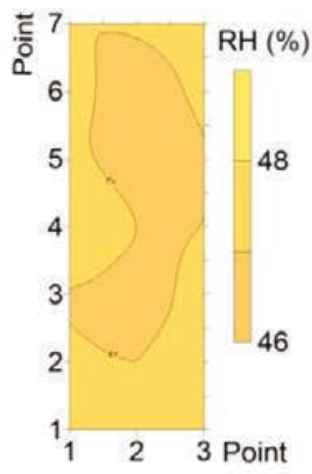

(J)

Figure 2. A-J) Maps of air temperature (T) and relative humidity ( $\mathrm{RH})$ for the horizontal plane at $1.2 \mathrm{~m}$, for daytime readings $(7$ a.m. to 6 p.m.) and the configurations. FC, fully closed greenhouse; MV, mechanical ventilation, with both exhaust fans connected; MV-S, mechanical ventilation with both exhausters and shading; MV1-NV, mechanical ventilation, with the lower exhaust fan on, and natural ventilation through the roof vent openings; MV2-NV, mechanical ventilation, with both exhaust fans turned on, and natural ventilation, through roof vent openings. 
shows the values corresponding to the standard deviation for each horizontal profile (or line) evaluated at $1.2 \mathrm{~m}, 2.4 \mathrm{~m}$, and $4.5 \mathrm{~m}$, for temperature and relative air humidity. Values presented in bold exceeded these set limits (range of $\pm 0.75^{\circ} \mathrm{C}$ for temperature and $\pm 3 \%$ relative humidity, Stichting Milieukeur, 2010, cited by Balendonck et al., 2010).

Mechanical ventilation, with both exhausts on (MV) or associated with shading (MV-S), provided a uniform temperature and relative humidity at the three heights assessed (Table 3 ).

When the greenhouse was entirely closed or mechanical ventilation was combined with natural ventilation, with the lower exhauster (MV1-NV) or with both exhausters (MV2-NV), homogeneity for air temperature and relative humidity was identified in the horizontal profiles at $1.2 \mathrm{~m}$ and $2.4 \mathrm{~m}$. This result agrees with Kittas et al. (2012), who found homogeneous conditions for the distribution of temperature and relative humidity (differences of $0.4^{\circ} \mathrm{C}$ and $1 \%$, concerning the centre of the environment), in a 160 $\mathrm{m}^{2}$ greenhouse in Greece, with ventilation mechanical and natural (movable side openings). Although at $4.5 \mathrm{~m}$ the standard deviation values above the limit established have indicated heterogeneous distribution conditions with natural ventilation configurations. We suppose that with the exhaust fan placed on the north side of the greenhouse and closer to the roof vent openings, air entered through the roof vent next to the exhauster, flowing contrary to the thermal effect and to the natural exhaustion through the roof vent openings, impairing the homogeneity distribution in the green- house. This supposition was illustrated on the vertical map distribution for natural ventilation.

The horizontal air temperature distribution maps show this homogeneity in all configurations for the profile at a height of 1.2 $\mathrm{m}$, shown in Figure 2. However, the configuration map with MV$\mathrm{S}$ is marked by a lighter area (Figure $2 \mathrm{C}$ ) with a temperature variation above the recommended limit. A failure in the fan connected to the PVC tube containing the air temperature might be the cause for this occurrence, making the air temperature measured at this point higher than in other points.

Figure 2 also shows horizontal distribution maps of relative air humidity to illustrate the homogeneity of the distribution in all configurations for the $1.2 \mathrm{~m}$-high profile. These maps show that the horizontal gradient formed followed the airflow through the mechanical exhaust only with mechanical ventilation, with both exhausters connected (Figure $2 \mathrm{G}$ ), or when associated with shading (Figure 2H), in agreement with Chen (2003). In contrast, the distribution of relative humidity in the environment was modified with the roof vent opening associated with the lower exhaust fan (Figure 2I) or with both exhaust fans turned on (Figure 2J). The variation is related to solar radiation, the transfer of heat and mass, and the dynamics of the air movement due to temperature differences.

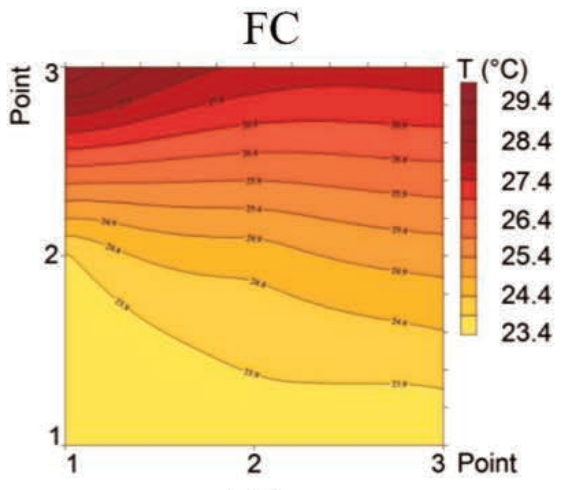

(A)

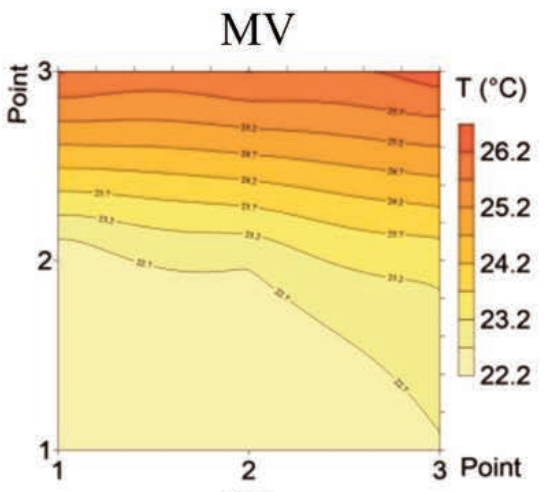

(B)

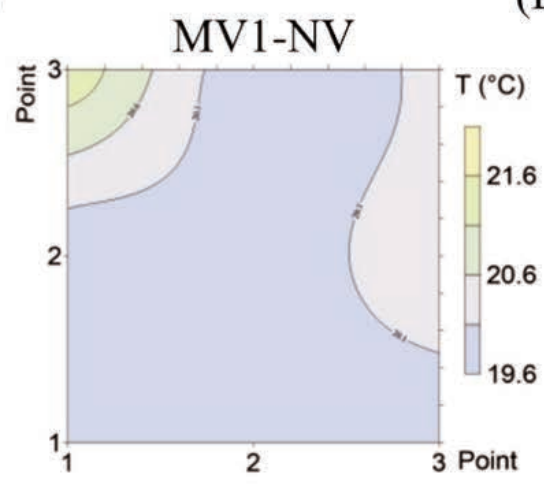

(D)

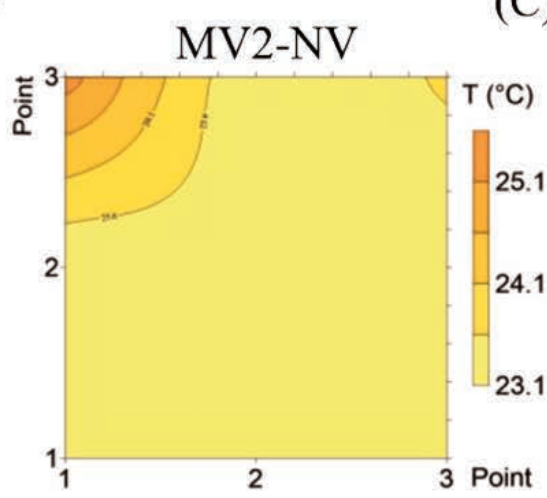

(E)

25.1

24.1

23.1

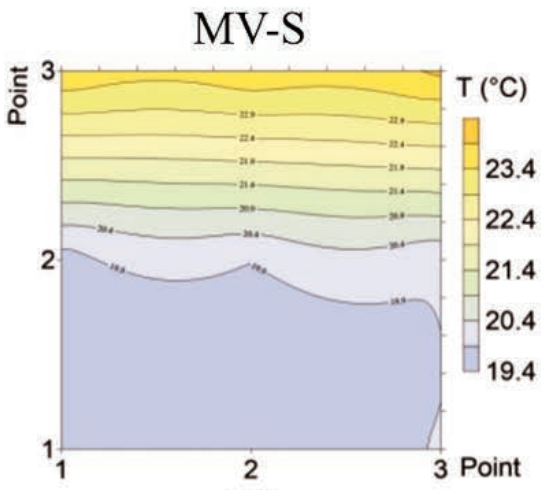

(C)
Figure 3. A-E) Maps of air temperature (T) for the central vertical plane, for daytime readings (7 a.m. to 6 p.m.) and the configurations. FC, fully closed greenhouse; MV, mechanical ventilation, with both exhaust fans connected; MV-S, mechanical ventilation with both exhausters and shading; MV1-NV, mechanical ventilation, with the lower exhaust fan on, and natural ventilation through the roof vent openings; MV2-NV, mechanical ventilation, with both exhaust fans turned on, and natural ventilation, through roof vent openings. 


\section{Vertical profiles analysis}

The vertical air temperature distribution maps show the main differences in gradients between the configurations with the greenhouse wholly closed $\left(4.52^{\circ} \mathrm{C}\right)$ (Figure $\left.3 \mathrm{~A}\right)$, with mechanical ventilation with both exhaust fans on $\left(3.86^{\circ} \mathrm{C}\right)$ (Figure $\left.3 \mathrm{~B}\right)$ and with mechanical ventilation associated with shading $\left(4.04^{\circ} \mathrm{C}\right)$ (Figure $3 \mathrm{C}$ ). In convection heat transfer, hot air rose, as it was less dense than cold air, but it tended to accumulate below the plastic cover. However, the results with the roof vent openings showed a reduction in the vertical temperature gradient, either associated with only the lower exhaust fan connected $\left(0.67^{\circ} \mathrm{C}\right)$ (Figure $\left.3 \mathrm{D}\right)$ or with both exhaust fans $\left(0.88^{\circ} \mathrm{C}\right)$ (Figure $\left.3 \mathrm{E}\right)$. In these cases, with the roof vent openings, due to the effect of the temperature difference, warm air, which was less dense than cold air, rose and was sucked out of the environment by natural exhaustion (López et al., 2011). However, the points with the highest temperature highlighted on the maps (Figure 3D and E) were located close to the upper exhauster. We suppose that with the exhaust fan placed on the northern side of the greenhouse and closer to the roof vent openings, air entered through the roof vent next to the exhauster, flowing contrary to the thermal effect and to the natural exhaustion through the roof vent openings, therefore, affecting the homogeneity distribution in horizontal profile at this height of the greenhouse.

Similarly to the air temperature maps, the vertical distribution maps of relative humidity showed the main differences with the greenhouse completely closed (-15\%) (Figure 4A), or only with mechanical ventilation with both exhaust fans turned on $(-11 \%)$ (Figure 4B), or when associating mechanical ventilation to shading $(-13 \%)$ (Figure 4C). The smallest vertical differences were obtained with natural ventilation through the roof vent openings associated with mechanical ventilation ( $-3 \%$ for both) (Figure 4D and $\mathrm{E}$ ). The associated use of natural and mechanical ventilation can favour the internal homogeneity of the meteorological elements (Kittas et al., 2012).

The use of the fixed shading system increased the vertical gradients of air temperature and relative humidity, due to heat accumulation above the screen, the reduction of air temperature and the increase of air relative humidity below the screen, in agreement with Coomans et al. (2013), who stated that the effect of an intensive use of screens is still unclear, as it can reduce energy demand and increase relative humidity inside the greenhouse.

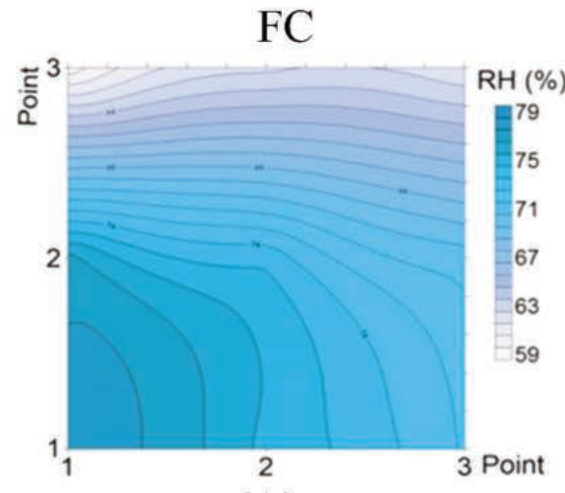

(A)

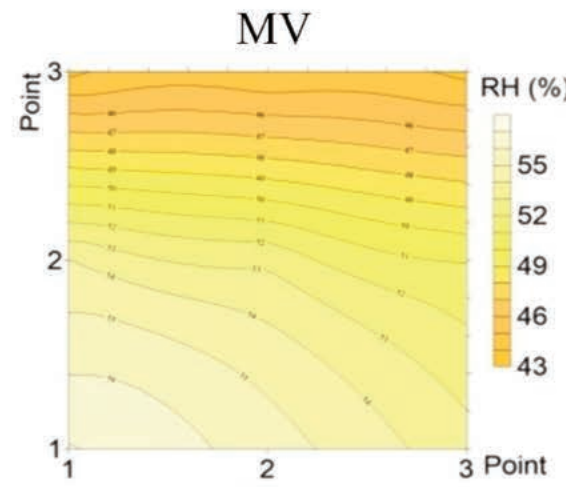

(B)

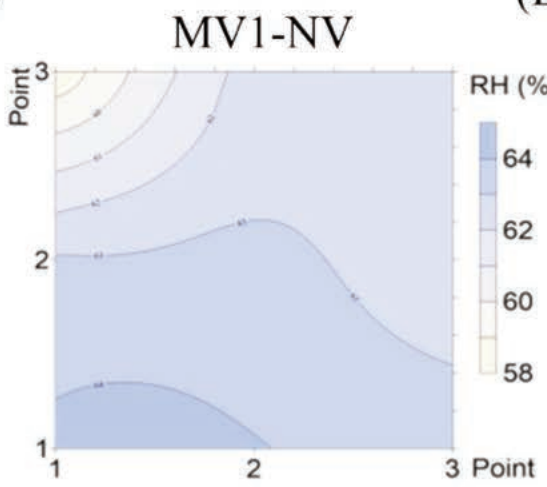

(D)

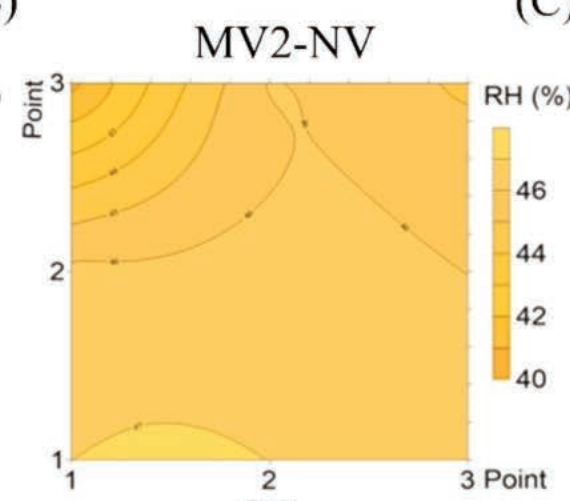

(E)

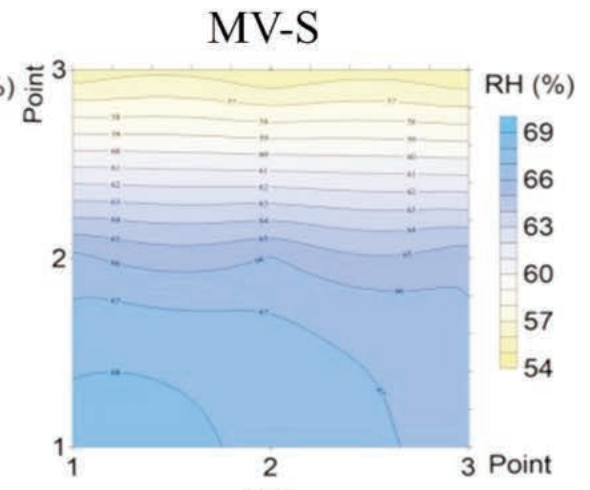

(C)

\footnotetext{
Figure 4. A-E) Maps of relative humidity $(\mathrm{RH})$ for the central vertical plane, for daytime readings (7 a.m. to 6 p.m.) and the configurations. FC, fully closed greenhouse; MV, mechanical ventilation, with both exhaust fans connected; MV-S, mechanical ventilation with both exhausters and shading; MV1-NV, mechanical ventilation, with the lower exhaust fan on, and natural ventilation through the roof vent openings; MV2-NV, mechanical ventilation, with both exhaust fans turned on, and natural ventilation, through roof vent openings.
} 


\section{Conclusions}

The use of a WSN made it possible to collect data 45 points in an appropriate manner. This would be hardly feasible with wired networks. The horizontal and vertical homogeneity of the meteorological elements, such as temperature and relative humidity, depended on the mechanism used in the greenhouse. Mechanical ventilation approximated the temperature and relative humidity of the indoor and outdoor air, with a homogeneous horizontal distribution throughout the microclimate. Opening the roof vent reduced vertical gradients of temperature and relative humidity. The association of the roof vent openings with mechanical ventilation was useful to achieve an adequate horizontal homogeneity of meteorological elements.

\section{References}

Balendonck J., van Os E.A., van der Schoor R., van Tuijl B.A.J., Keizer L.C.P. 2010. Monitoring spatial and temporal distribution of temperature and relative humidity in greenhouses based on wireless sensor technology. Proc. International Conference on Agricultural Engineering, AgEng 2010: towards environmental technologies. Wageningen University and Research Center, Clermont-Ferrand, France, 443p.

Balendonck J., Sapounas A.A., Kempkes F., van Os E.A., van der Schoor R., van Tuijl B.A.J., Keizer L.C.P. 2014. Using a wireless sensor network to determine climate heterogeneity of a greenhouse environment. Acta Hortic. 1037:539-46.

Bojacá C.R., Gil R., Gómez S., Cooman A., Schrevens E. 2009. Analysis of greenhouse air temperature distribution using geostatistical methods. Trans. ASABE. 52:957-68.

Chen C. 2003. Prediction of longitudinal variations in temperature and relative humidity for evaporative cooling greenhouses. Agricult. Engine. J. 12:143-64.

Coomans M., Allaerts K., Wittemans L., Pinxteren D. 2013. Monitoring and energetic performance of two similar semiclosed greenhouse ventilation systems. Energy Convers. Manage. 76:128-36.

García-Ruiz R.A., López-Martínez J., Blanco-Claraco J.L,. PérezAlonso J., Callejón-Ferre A.J. 2018. On air temperature distribution and ISO 7726-defined heterogeneity inside a typical greenhouse in Almería. Comput. Electron. Agricult. 151:26475.

Ferentinos K.P., Katsoulas N., Tzounis A., Bartzanas T., Kittas C. 2017. Wireless sensor networks for greenhouse climate and plant condition assessment. Biosyst. Engine. 153:70-81.

Kittas C., Katsoulas N., Papa K., Thanasenaris A., Bartzanas T. 2012. Improvement of greenhouse microclimate distribution by means of air mixing fans. Acta Horticult. 927:589-94.

Kutta E., Hubbart J. 2014. Improving understanding of microclimate heterogeneity within a contemporary plant growth facili- ty to advance climate control and plant productivity. J. Plant Sci. 2:167-78.

López A., Valera D.L., Molina-Aiz F.D. 2011. Sonic anemometry to measure natural ventilation in greenhouses. Sensors. 11:9820-38.

López A., Valera D.L., Molina-Aiz F.D., Peña A. 2013. Effectiveness of horizontal air flow fans supporting natural ventilation in a Mediterranean multi-span greenhouse. Sci. Agric. 70:219-28.

López-Martínez J., Blanco-Claraco J.L., Pérez-Alonso J., Callejón-Ferre A.J. 2018. Distributed network for measuring climatic parameters in heterogeneous environments: application in a greenhouse. Comput. Electron. Agricult. 145:105-21.

Narasimhan V.L., Arvind A.A., Bever K. 2007. Greenhouse asset management using wireless sensor-actor networks. Proc. International Conference on Mobile Ubiquitous Computing, Systems, Services and Technologies. DOI: 10.1109/UBICOMM.2007.43

Oz H., Atilgan A., Buyuktas K., Alagoz T. 2009. The efficiency of fan-pad cooling system in greenhouse and building up of internal greenhouse temperature map. Afr. J. Biotechnol. 8:543644.

Pawlowski A., Guzman J.L., Rodríguez F., Berenguel M., Sánchez J., Dormido S. 2009. Simulation of greenhouse climate monitoring and control with wireless sensor network and eventbased control. Sensors. 9:232-52.

Sapounas A.A., Nikita-Martzopoulou C., Spiridis A. 2008. Prediction the spatial air temperature distribution of an experimental greenhouse using geostatistical methods. Acta Hortic. 801:495-500.

Stichting Milieukeur. 2010. Certification Groen Label Kas - Level B = CertificatieschemaGroen Label Kas - Niveau B - 2010 (in Dutch). Available from: http://www.smk.nl Accessed: Aug 15, 2014.

Suay R., López S., Granell R., Moltó E., Fatnassi H., Boulard T. 2008. Preliminary analysis of greenhouse microclimate heterogeneity for different weather. Acta Hortic. 797:103-9.

Tanny J. 2013. Microclimate and evapotranspiration of crops covered by agricultural screens: A review. Biosyst. Engine. 114:26-43.

Teitel M., Atias M., Barak M. 2010. Gradients of temperature, humidity and $\mathrm{CO} 2$ along a fan-ventilated greenhouse. Biosyst. Engine. 106:166-74.

Vox G., Losito P., Valente F., Consoletti R., Scarascia-Mugnozza G., Schettini E., Marzocca C., Corsi F. 2014. A wireless telecommunications network for real-time monitoring of greenhouse microclimate. J. Agric. Engine. XLV:237.

WMO (World Meteorological Organization). 1953. Commission for synoptic meteorology. Secretariat of the World Meteorological Organization, Geneva, Switzerland.

Zorzeto T.Q., Leal P.A.M. 2017. Wireless sensor network to map the meteorological variability in a greenhouse with evaporative cooling. Acta Hortic. 1154:213-20. 